\title{
LOS DERECHOS INDIVIDUALES
}

\author{
POR \\ JUAN BENEYTO
}

El 18 de junio de 1837 fue promulgada una nueva Constitución de la Monarquía española, en sustitución del Estatuto Real de 1834 y como revisión del texto fundamental aprobado en Cádiz en 1812. Aunque tuvo breve vigencia, su significación ofrece interés y su texto representa un hito importante en el proceso codificador del Derecho político. De entre los temas que aborda hay uno que vamos a traer a estas páginas y que merece ser colocado destacadamente: el relativo al nuevo tratamiento que se da a esos Derechos individuales, que luego hemos llamado fundamentales y aun, finalmente, humanos.

La Constitución de 1837 se presenta, en efecto, como una revisión de la de $1812^{1}$. Su elaboración estuvo precedida de la puesta en vigor de esta última, por Decreto de la Reina gobernadora con fecha de 13 de agosto de 1836. Casi simultáneamente -el 21 de ese mismo mes, apenas transcurridos siete días desde tal reposición- se convocaron elecciones, de acuerdo con el texto de Cádiz, pero con algunas modificaciones de legalidad discutible ${ }^{2}$. El restablecimiento de la Constitución de 1812 es consecuencia del motín de $\mathrm{La}$ Granja, que incita a la Reina a cesar a Istúriz como jefe del Gobierno y sustituirle por Calatrava ${ }^{3}$. Pero el Gabinete regido por Istúriz había trabajado ya desde su investidura, el 15 de mayo, en la preparación de un Proyecto de ley fundamental, que fue hecho público el 20 de julio.

Es este Proyecto - $\mathrm{y}$ no el Estatuto Real - lo que realmente se tiene en cuenta para preparar la nueva Constitución. Entre otras cosas porque el Esta-

${ }^{1}$ Constitución de la Monarquía española, promulgada en Madrid a 18 de junio de 1837. I. pr.: «Siendo la voluntad de la nación revisar, en uso de su soberanía, la Constitución promulgada en Cádiz», las Cortes generales congregadas a este fin...

Para éste y los demás textos citados véase Jorge de Esteban, ed., Constituciones españolas y extranjeras, Madrid, 1977.

${ }_{2}$ Ásí lo estima Joaquín Tomás Villarroya, El proceso constitucional, 1834-1843, en el vol. 34 de la Historia de España fundada por don Ramón Menéndez Pidal, Madrid, 1981 , pág. 3

${ }^{3}$ Modesto Lafuente, Historia general de España, Barcelona, 1890, tomo 21, pág. 45. 
tuto no da pie para más: pues no es propiamente un código político, sino una disposición, del más alto rango, limitada a regular las Cortes Generales ${ }^{4}$.

Acudiendo al Proyecto, advertimos que las fórmulas finalmente asumidas por la Constitución de 1837 proceden directamente de aquél y precisamente en el área que aquí nos importa, pues si lo que califica como importante el texto de 1837 es el tratamiento que da a los derechos individuales, su sistematización deriva del Proyecto.

Los autores no se muestran unánimes en la calificación de este aporte. Mientras Xifra nos dice que ofrece «una declaración de derechos» ${ }^{5}$, Sánchez Agesta no ve tan claro que sea declaración, sino tan sólo expresión de las consecuencias jurídicas de tales libertades ${ }^{6}$, y Tomás Villarroya concreta: se trata de una Constitución muy estimable, con texto sobrio y completo que «regula ordenadamente» los derechos individuales que la Constitución de Cádiz mencionaba de manera dispersa y que el Estatuto Real silenciaba ${ }^{7}$.

Así, de cualquier modo, lo que sí encontramos es la presencia del primer texto constitucional español donde los derechos individuales son objeto de un tratamiento específico, llamémosle o no declaración.

El Gabinete presidido por Francisco Javier de Istúriz había preparado, en el breve plazo de su gestión gubernativa, ese Proyecto de revisión de la Constitución de 1812 que es el cañamazo donde se borda el texto de 1837. La redacción del Proyecto fue obra de Antonio Alcalá Galiano, discutida y aprobada por el Consejo de Ministros. Su texto fue entonces dado a la imprenta ${ }^{8}$ y es recogido más tarde por el marqués de Miraflores en sus Memorias ${ }^{9}$ y por los continuadores de la Historia de Lafuente, Juan Valera, Andrés Borrego y Antonio Pirala ${ }^{10}$.

Decimos que el Proyecto fue obra de Alcalá Galiano no sólo porque éste gozaba de la amistad más próxima y entrañable del presidente Istúriz ${ }^{11}$, sino porque él mismo lo confiesa en las Memorias publicadas por su hijo. Afirma allí que hecho miembro del Gobierno y titular de una cartera sin problemas,

${ }^{4}$ Es realmente una ley orgánica del Parlamento, en la que se señalan las calidades de los dos estamentos establecidos, de próceres y de procuradores. No hay allí un solo precepto sobre los ciudadanos, salvo el que señala la posibilidad de ser procurador o de intervenir en la elección de procuradores.

${ }_{5}$ Jordi Xifra, Constitucions, partits $i$ autonomies, Barcelona, 1981, p. 39: «El primer titol reuneix, per primera vegada, una declaració de drets fónamentals dels espanyols.»

6 Luis Sánchez Agesta, Historia del constitucionalismo español, Madrid, 1978, pág. 266. Expresa únicamente las consecuencias jurídicas de la libertad de imprenta, el derecho de petición, la igualdad ante la ley y el juez, la seguridad personal y la propiedad «sin proclamar estos principios».

${ }_{7}$ El proceso constitucional, cit., pág. 43.

8 «Que ha corrido impreso», declara Álcalá Galiano en sus Memorias, loc. cit. en la nota 12 .

- Marqués de Miraflores, Memorias para escribir la bistoria contemporánea, Madrid, 1843, págs. 633-645.

${ }_{10}$ Lafuente, Historia generai de España, tomo 21, págs. 75-80.

it Sobre esta amistad, F. Ximénez de Sandoval, Antonio Alcalá Galiano, Madrid, 1943, págs. 123, 199, 206, 346, 398... Istúriz le hizo diputado y finalmente ministro. 
opinó que había que disolver las Cortes y preparar una nueva Constitución: «En el Ministerio - declara - trabajé casi solo un proyecto de reforma de lás leyes fundamentales o dígase de la Constitución, que ha corrido impreso» ${ }^{12}$. A éste Proyecto habrá, pues, que referirse para examinar, punto por punto, las regulaciones que nos interesan.

$* * *$

La Constitución de Cádiz declara que la nación está obligada a conservar y a proteger por leyes sabias y justas la libertad civil, la propiedad y los demás derechos legítimos «de todos los individuos que la componen» ${ }^{13}$.

Juntamente con estos derechos, no proclamados. pero sí señalados, andan los deberes: amar a la patria, ser fieles a la Constitución,.:contribuir a los gastos y defender a la patria con las armas ${ }^{14}$. Por lo demás, hay una restricción clarísima a un derecho posteriormente muy desarrollado: el de libertad confesional. Los constituyentes de Cádiz insisten en la línea tradicional de la unidad religiosa al establecer que la religión católica estará protegida y toda otra confesión será prohibida ${ }^{15}$.

En este punto la Constitución de 1837 abandona aquella línea y frente a las declaraciones dogmatizantes acepta las situaciones fácticas. Mientras en 1812 se declaraba que la religión católica «es y será perpetuamente la católica, apostólica, romana, única verdadera», en 1837 se reconoce que dicha religión es «la que profesan los españoles», y en tal inteligencia, la nación se obliga a mantener el culto y sus ministros ${ }^{16}$. El tema no había sido abordado por el Proyecto . Istúriz.

Por lo que toca al libre acceso a los cargos públicos, Cádiz reconocía a los españoles el derecho a «obtener empleos municipales» ${ }^{17}$. Pero mientras este texto señalaba vagamente que «sólo los que sean ciudadanos podrán obtener empleos municipales y elegir para ellos en los casos señalados por la ley», el de 1837 muestra un contenido más amplio: «Todos los españoles son admisibles a los empleos y cargos públicos según su mérito y capacidad» ${ }^{18}$. La mediación del Proyecto Istúriz me parece clara: había propuesto que «los españoles, sin distinción de nacimiento, son admisibles a los destinos y empleos eclesiásticos, civiles y militares» ${ }^{19}$.

Entre 1812 y 1837 se pierde el buen propósito de cuidar la educación pública. Cádiz, al ocuparse de las razones que hacen decaer la calidad de ciudadano, señala: por interdicto judicial, por quiebra o deuda a los caudales públicos, por el estado de sirviente doméstico, por no tener empleo, oficio o modo de vivir conocido, o por hallarse procesado..., y anuncia que «a partir de 1830 , los que no sepan leer y escribir no podrán entrar en el ejercicio de gina 519

${ }^{12}$ Memorias de Alcalá Galiano, publicadas por su hijo, Madrid, 1886, tomo 2. ${ }^{\circ}$, pá-

${ }_{13}$ Constitución de 1812 , art. $40^{\circ}$

${ }^{14}$ Constitución cit., arts. $50^{\circ}$ y $60^{\circ}$

${ }^{15}$ Constitución cit., art. 12.

16 Constitución de 1837, art. 11.

${ }^{17}$ Constitución cit., art. 23.

${ }^{18}$ Constitución de 1837 , art. 5.

19 Proyecto Istúriz, art. 2. 
los derechos de ciudadano» ${ }^{20}$. En 1837 tales limitaciones se-reducen (por adquirir naturaleza en país extranjero o admitir empleo de otro gobierno sin licencia del rey), y se abandona la idea de exigir un nivel mínimo de educación. Tampoco se habla en 1837 del deber estatal de proporcionar instrucción. Cádiz había formulado el antecedente del derecho a la cultura, al instaurar escuelas públicas en todo el territorio nacional: «En todos los pueblos - se dijo- se establecerán escuelas de primeras letras en las que se enseñará a los niños a leer, escribir y contar, y el Catecismo de la religión católica, que comprenderá también una buena exposición de las obligaciones civiles» ${ }^{21}$. El precepto es desatendido tanto en el Proyecto Istúriz como en el texto de 1837.

Dos disposiciones relativas al orden procesal —el derecho a ser juzgado por tribunal competente y el de no ser preso sin previa información ${ }^{22}$ - se funden en el Proyecto Istúriz ${ }^{23}$ y pasan a la Constitución de $1837^{24}$.

Va de uno a otro, sin más modificación que la exigencia de mayores concreción y detalle, la prohibición de confiscar los bienes. Basta dar un repaso a cualquier historia de las banderías - y no sólo de las guerras interioresdel siglo XIX para que veamos con qué frecuencia era éste un tema vivo ${ }^{25}$. En 1812 se había escrito en la ley fundamental: «Tampoco se impondrá la pena de confiscación de bienes» ${ }^{26}$. En 1837 se insistió: no se impondrá jamás la pena de confiscación de bienes; añadiéndose: ningún español será privado de su propiedad sino por causa justificada de utilidad común, previa la correspondiente indemnización ${ }^{27}$. Por medio anda el Proyecto Istúriz, que señala esos dos extremos ${ }^{23}$.

También arranca de Cádiz el derecho de petición. Todo español —se establece en la Constitución de 1812 - tiene derecho a representar a las Cortes o al Rey ipara reclamar la observancia de la Constitución! ${ }^{29}$. Es un artículo concreto y limitado además a una función, casi una acción pública en la tarea ahora asignada al Tribunal Constitucional y al Defensor del Pueblo.

El Proyecto Istúriz amplía el concepto: todo español tiene libertad «de hacer y dirigir peticiones al Rey y a las Cortes sobre negocios privados o públicos..., pero no formando cuerpo colectivo, ni en forma y representación de otra persona» ${ }^{30}$. La Constitución de 1837 confirma y aplaza: todo español tiene derecho a dirigir peticiones «por escrito» a las Cortes o al Rey... «como determinen las leyes ${ }^{31}$.

${ }^{20}$ Constitución de 1812, art. 25.

${ }^{21}$ Constitución cit., art. 366.

${ }_{22}$ Constitución cit., arts. 247 y 287.

${ }^{23}$ Proyecto Istúriz, art. 5.: No podrá ser arrestado ni preso sino según las fórmulas que propongan las leyes, ni condenado sin sentencia dada por la autoridad judicial competente.

${ }^{24}$ Constitución de 1837, art. 9.: Ningún español puede ser procesado ni sentenciads sino por juez o tribunal competente, en virtud de leyes anteriores al delito y en la forma que éstas prescriban.

${ }^{25}$ Cf. Modesto Lafuente, Historia general, cit., vol. 21, passim.

${ }^{26}$ Constitución de 1812, art. 304.

${ }_{27}$ Constitución de 1837, art. 10.

${ }^{28}$ Proyecto Istúriz, art. 6.

${ }^{29}$ Constitución de 1812, art. 373.

${ }^{30}$ Proyecto Istúriz, art. $4 .^{\circ}$

${ }^{31}$ Constitución de 1837 , art. $3 .^{\circ}$ 
Pero donde la aportación del texto que aquí nos interesa resulta más relevante es en el punto álgido en aquella época, y aun siempre, de la llamada libertad de imprenta.

Partiendo de Cádiz, advertimos que en su arranque inicial, en 1812, esta: libertad se sujeta a ley y se proscribe todo mecanismo censorio. El enfrentamiento con los juzgados de imprenta, las censuras gubernativas y las presiones inquisitoriales constituye el punto de partida: todos los españoles - se dejará dicho alli- tienen libertad de escribir, imprimir y publicar sus ideas politicas, sin necesidad de licencia, revisión o aprobación alguna anterior a la publicación, bajo las restricciones y responsabilidades que establezcan las leyes ${ }^{32}$.

El Proyecto Istúriz aporta una novedad, que recoge la nueva Constitución: suprime el adjetivo «políticas», aplicado a las ideas cuya difusión es autorizada. Por lo demás; casi repite el texto de $1812^{33}$. Hay así una notable ampliación, pues anteriormente las ideas religiosas, por ejemplo, seguían sometidas a censura. Con tal redacción pasa el texto a la Constitución de 1837, donde hay referencia concreta a la supresión de la previa censura y donde se añade que la calificación de los delitos de imprenta corresponderá exclusivamente a los Jurados ${ }^{34}$.

Estamos, pues, ante un precepto importante, capaz de hacernos valorar de modo positivo la significación del nuevo tratamiento. El derecho de libertad de imprenta queda así ligado al de libertad de pensamiento y - contra lo que suele decirse - se separa del moderno derecho a ser informado y aun de dar y de recibir información: no son las noticias, sino las ideas, lo que nutre, durante nuestro siglo XIx, aquella trascendente libertad ${ }^{35}$.

$\mathrm{La}$ exigencia de que las incidencias del derecho de imprenta se atribuyan a los Jurados es consecuencia del programa progresista, que entendía que los tribunales ordinarios estaban demasiado vinculados a la Administración. Pero como en la práctica conducía con frecuencia a una impunidad no pudo mantenerse en la reglamentación consiguiente. Viene así, limitando la aplicación del principio, el Reglamento de 17 de octubre de aquel mismo año de 1837.

Con anterioridad a los preceptos de la nueva Constitución, el Reglamento de 4 de enero de 1834, obra de Javier de Burgos, había regulado lo que salía fuera de las «ideas políticas» autorizadas, sancionando las ofensas a la religión católica y el detrimento del bien general. Estas dos áreas se presentaban como amplísima explanada, capaz de desmontar buena parte de las esperanzas derivadas de la Constitución precedente, aunque el legislador dijese que quedaban a salvo las relativas a la ilustración, «tan necesaria a la prosperidad de estos reinos» ${ }^{36}$. Ahora, tras el texto de 1837, el Reglamento de 17 de octubre es claramente limitativo. Formula el principio de la responsabilidad del editor o editores del periódico donde se ejercite la libertad de imprenta, y fija la con-

${ }^{32}$ Constitución de 1812, art. 371.

${ }^{33}$ Proyecto Istúriz, art. 3.

${ }^{34}$ Constitución de 1837 , art. $20^{\circ}$

${ }_{35}$ Cfr. Beneyto, «Los orígenes del derecho a ser informado», en Persona y Derecho, V, 1978, pág. 20.

${ }_{36}$ Cfr. A. Rumeu de Armas, Historia de la censura literaria gubernativa en España, Madrid, 1940, pág. 198, y F. Cendán, Historia del derecho de prensa e imprenta, Madrid, 1974, págs. 116-122. 
dición de que tales editor o editores sean contribuyentes directos al corriente del pago ${ }^{37}$. No hay sino que esperar unos meses, poco más de año y medio, para que aun ese Reglamento parezca poco: así, en el de 5 de junio de 1839 se excitan el celo y la vigilancia de los jefes políticos y de las demás autoridades para exigir el cumplimiento de las disposiciones legales precedentes ${ }^{38}$, visto que el derecho concedido por la Constitución había degenerado «en un desenfreno tan funesto y lastimoso que hiere y mata la misma libertad» ${ }^{39}$.

$$
* * *
$$

En conclusión, aun con su breve vigencia y bien atendidos los matices con que atempera los preceptos, la importancia del texto de 1837 es innegable por lo que toca al tratamiento de los derechos que hemos acabado llamando fundamentales o humanos, ya que aquella Constitución, dando término a las posiciones más extremosas, consolidó de modo definitivo el régimen constitucional.

A partir de 1837 - señalan Solé Tura y Aja-, las distintas fuerzas políticas, una vez acabada la guerra carlista, establecerán regímenes distintos, pero lo harán siempre «dentro del sistema constitucional» y en él - junto al principio de la soberanía nacional, decisivo para acabar con el absolutismo de los monarcas - se mantendrá de manera permanente una declaración de los derechos de los ciudadanos ${ }^{40}$.

En este sentido, con declaración más o menos definida, pero con claro tratamiento específico, la Constitución de 1837 marca un cambio sustancial e inicia una etapa merecedores de estudio y de consideración.

${ }^{37}$ Cendán, ob. cit., págs. 122-124.

${ }^{38}$ Ibíd., págs. 124-126.

${ }^{39}$. Texto en Cendán, ob. cit., pág. 124.

${ }^{40}$ Jordi Solé Tura y Eliseo Aja, Constituciones y periodos constituyentes en España, Madrid, 1977, pág. 33. 